\title{
Intraocular live male filarial Loa loa worm
}

\author{
André Omgbwa Eballe \\ Emillienne Epée ${ }^{2}$ \\ Godefroy Koki \\ Didier Owono ${ }^{2}$ \\ Côme Ebana Mrogo² \\ Assumpta Lucienne Bella ${ }^{2}$ \\ 'Gynaeco Obstetric and Paediatric \\ Hospital of Yaoundé, Yaoundé, \\ Cameroon; ${ }^{2}$ Faculty of Medicine \\ and Biomedical Sciences, University \\ of Yaoundé, Yaoundé, Cameroon
}

\begin{abstract}
We report a case of Loa loa filariasis in an 8-month-old child who presented with a 3-month history of irritated acute red eye and insomnia. Examination revealed a living and active adult Loa loa worm in the anterior chamber of the left eye. The worm was extracted under general anesthetic.
\end{abstract}

Keywords: Loa loa, red eye, Cameroon

\section{Introduction}

Loa loa is commonly seen in the adnexae of the eye and subcutaneous tissues. Clinicians have long believed that the only ocular accident that occurs in this pathology is the migration of an adult worm across the conjunctiva. Recent observations describe a rare entity, the intraocular migration of an adult worm. In this case, an 8-month-old baby received treatment in the emergency rooms of the Yaoundé Gaeneco Obstetric and Paediatric Hospital (YGOPH), Yaoundé, Cameroon.

\section{Case report}

A male baby aged 8 months and weighing $8 \mathrm{~kg}$ presented to the clinic in February 2008. He was born in Ebengon, a small village in South Cameroon at the border with Equatorial Guinea. He is the second child of a 21-year-old farmer mother and a 30-year-old salesman father. The child was brought to the consultation with a 3-month history of irritability, insomnia, painful red eye, photophobia, and tearing. The right eye examination revealed blepharospasm, significant lid edema, hyperhemic conjunctiva, and a mobile living whitish organic foreign body in the anterior chamber (Figure 1). The left eye was quiet with no abnormality detected. Results of a general examination by a pediatrician were reported to be normal with no onchocercoma. A multiple blood smear with hematoxylin Giemsa stain, before and after hemolysis, using saponine $2 \%$ found no microfilaria on multiple mid-day samples; a full blood count revealed moderate hypereosinophilia, and a skin snip test for onchocerciasis was negative. The baby was hospitalized, and the midnight blood sample was also tested for lymphatic filariosis Wuchereria bancrofti and Brugia malayi, which have nocturnal periodicity; this exam was negative. Pre-operative hemostasis was within normal limits. After obtaining parental consent, the eye was examined under general anesthesia using an operating biomicroscope. This examination revealed in the right eye, a moderate edema of the cornea, a white mobile worm in the anterior chamber, a hypopyon, a miosis with posterior synechiae of $360^{\circ}$, a cataract, and high intraocular pressure (of $30 \mathrm{~mm} \mathrm{Hg}$ as measured with tonopen). Results of an examination of the left eye were normal. The surgical intervention consisted of a limbal-based incision between 11 and 13 o'clock, expulsion of the worm anterior chamber, washout followed by a capsulotomy releasing of synechia in $360^{\circ}$, and a lens washout (Figures 2, 3). Because sectorial iris atrophy was noted, posterior capsulorhexis was not performed and no intraocular implant inserted. Instead, a peripheral iridectomy was performed at 12 o'clock and the wound was sutured with 10/0 black silk. A subconjuctival injection of a combination of dexamethason and gentamicin was given. Post-operative treatment included bethamethason 


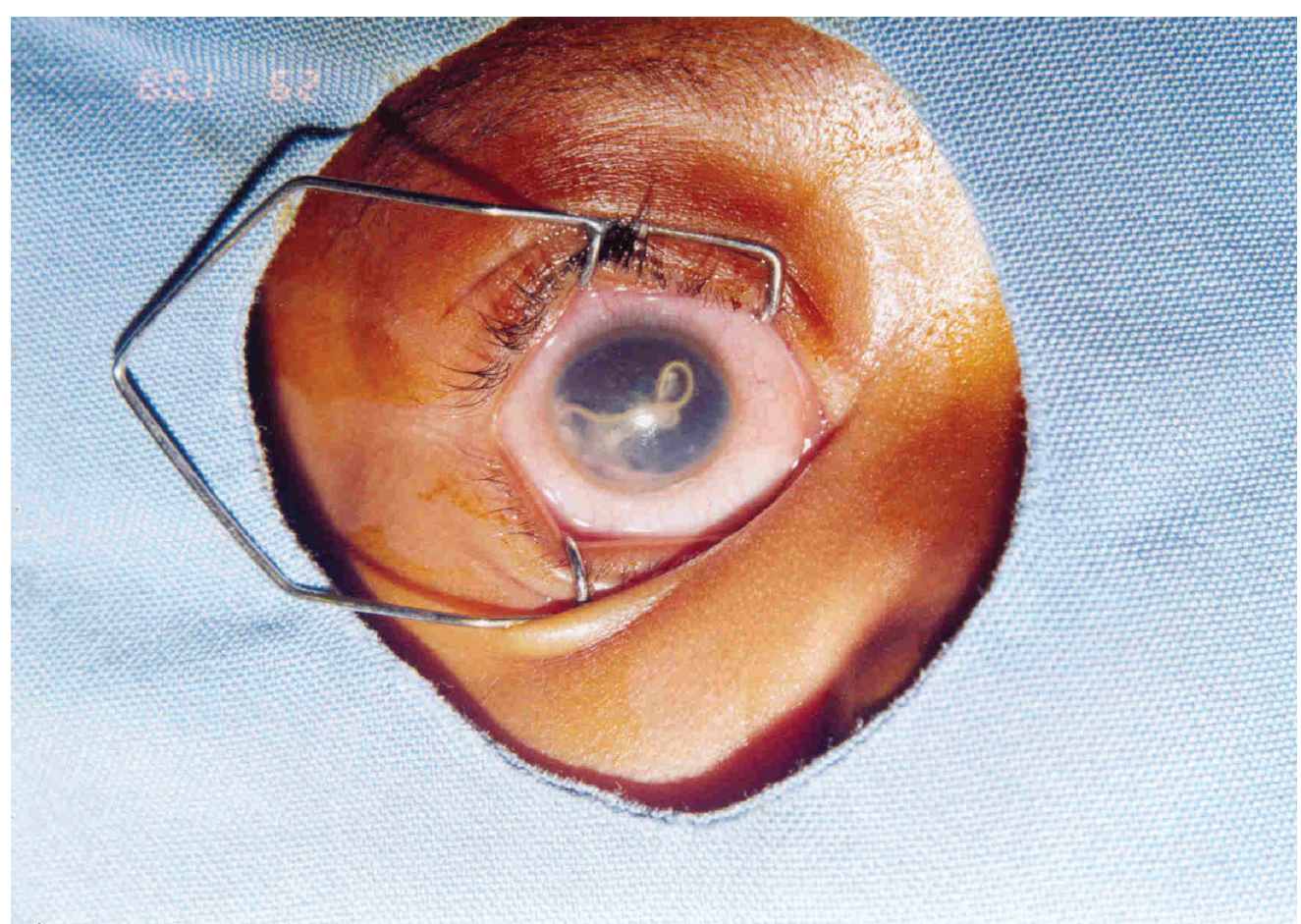

Figure I Intraocular adult Loa loa worm.

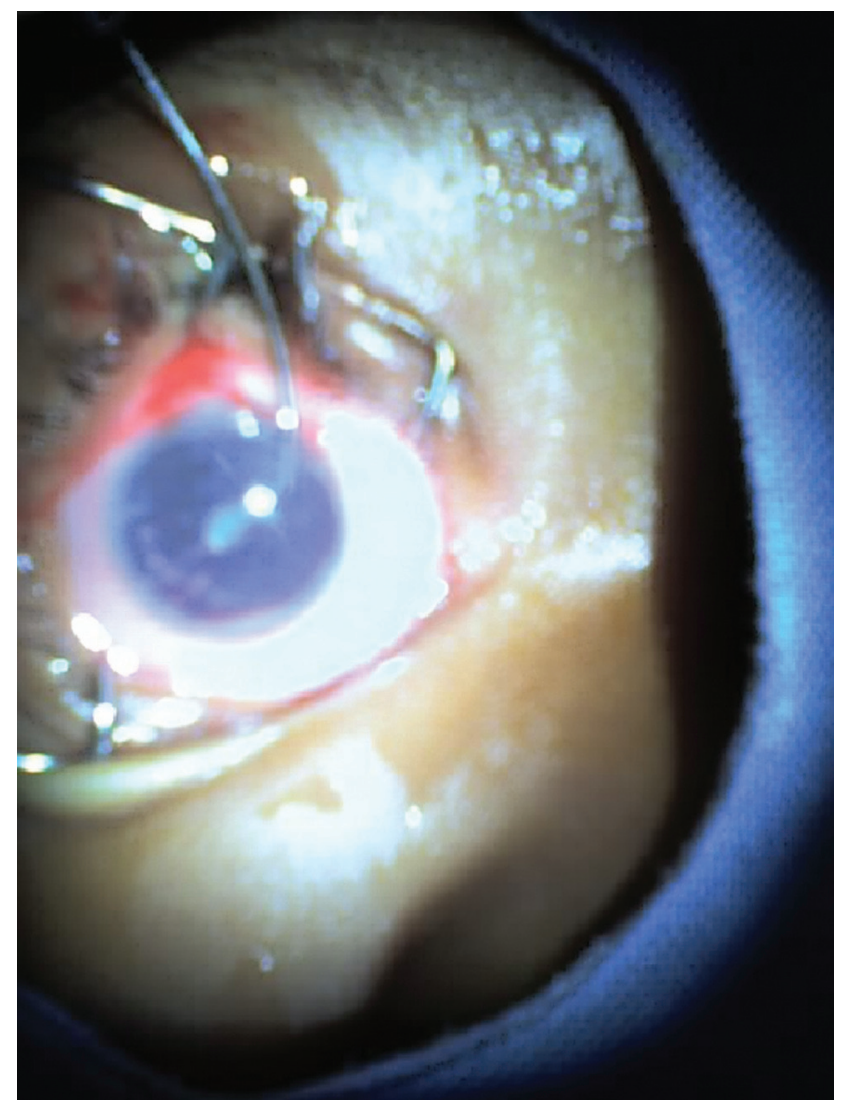

Figure 2 Eye with secondary cataract after removing worm.

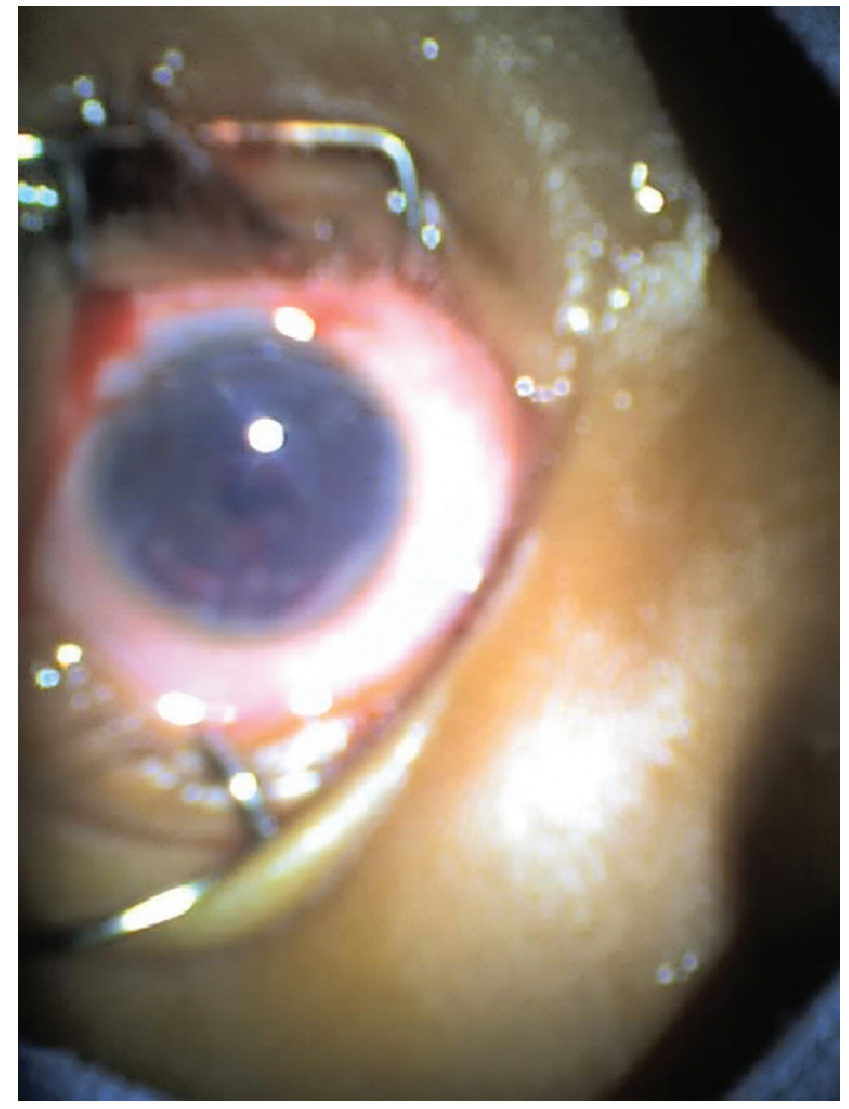

Figure 3 Eye after extracapsular surgery. 
20 drops twice daily, a topical combination of dexamethason and neomycine four times per day, and atropine $0.5 \%$ drops twice daily. The doses of topical steroid treatment were tapered down progressively over 60 days. Despite negative parasitemia, we decided to treat with diethylcarbamazine (DEC) for 21 days. The follow-up was good although the cornea remained slightly troubled at the end of the treatment.

Laboratory analysis of the worm revealed it to be $20 \mathrm{~mm}$ long and $0.5 \mathrm{~mm}$ diameter. Microscopy showed that the body of the worm was covered with a thick cuticle which was unstriated, the anterior extremity had a simple mouth, and the posterior extremity was rounded and showed small sessile caudal papilla and spicule. These findings with the absence of microfilariae in the peripheral blood films, suggested the identity of the worm to be an adult male Loa loa. The aqueous humor instead was free of microfilaria.

\section{Discussion}

The presence of an intraocular adult Loa loa worm in the anterior chamber was documented for the first time in Cameroon in 1972 by Lucot and Chovet (1972) in a 14-month-old child in Yaoundé. No laboratory test was done to confirm the nature of the worm, but the authors made a presumptive diagnosis of loiasis. In our case, the child presented with 3 months of symptoms, so that we presume that the clinical signs began when the child was 5 months of age. Vedy and colleagues (1988) report that the maturation of microfilaria taken from a hematophage meal is completed within 10 to 12 days in the body of the Chrysops vector. After a human becomes infected from a fly bite, the final maturation process is completed within 3 months. Based on this timeline, we can assume that the baby in our case was infected with Loa loa at 2 months of age. The route for intraocular penetration is still unknown. Two hypotheses have been proposed by Vedy and colleagues (1988): the adult worm may penetrate through the sclera or the metacyclic larvae may mature in the ocular region.

Our case was a baby, similar to the first case described in Cameroon by Lucot and Chovet (1972) in which the baby was 14 months old. Our patient was younger than other children discussed in many case reports we found in our review of the literature.

Our patient had similar symptoms to the cases reported by Osuntokun and Olurin (1975), Barua and colleagues (2005), Satyavani and Rao (1993), and Carme and colleagues (1984), with no detectable levels of microfilaremia and no history of visualization of subconjunctival or subcutaneaous migration of microfilaria. This result suggests that the maturation in vivo of male microfilarium that did not undergo reproduction. Uveitis with hypopion and secondary cataract with corneal oedema were the anatomic complications of our case, which was diagnosed after three symptomatic months. The two cases reported by Osuntokun and Olurin (1975) reported complications of painful blind eye and chronic anterior uveitis and were diagnosed after 5 and 6 months, respectively. The case reported by Satyavani and Chinnaya Rao (1993) was diagnosed after 15 days and resulted in no anatomic sequelae. Despite negative parasitemia, we decided to treat with DEC like many other clinicians, which was justified by the hyperendemicity of Loiasis in the region. Loiasis is very common in the rain forest of central and west Africa (Collee et al 1996). The high frequency of loiasis in this area led Vedy and colleagues (1988) to attest that there is no consultation day without removal of subconjonctival migration of adult Loa loa worm.

\section{Conclusion}

This second case of intraocular adult Loa loa worm documented in Cameroon, a hyperendemic area, may raise public health concerns about the ocular complications of loiasis. According to Vedy and colleagues (1988), Loa loa infection, whose disease burden is not exactly known, should be considered a serious parasitic infection that may lead to blindness. It is also important to look for cardiopulmonary, neurologic, and kidney complications. These general complications are seen in patients with chronic high parasitemia, which has been shown to result from immunological reactions (Vedy et al 1988).

\section{Disclosure}

The authors report no conflicts of interest in this work.

\section{References}

Barua P, Barua N, Hazarika NK, et al. 2005. Loa loa in the anterior chamber of the eye: a case report. Indian J Med Microbiol, 23:59-60.

Carme B, Kaya-Gandziami, Pintart D, et al. 1984. Localisation dans la chambre antérieure de l'œil de la filaire loa loa, à propos d'une observation. Acta Tropica, 41:265-9.

Collee GJ, Fraser AG, Marmion BP, et al. 1996. Practical Medical Microbiology, 14th edition. Oxford: Churchill Livingstone.

Lucot J, Chovet M. 1972. [Loase intra oculaire, à propos d'une observation.] Med Trop (Marseille), 32:523-5.

Osuntokun O, Olurin O. 1975. Filarial worm (Loa loa) in the anterior chamber. Report of two cases. Br J Ophthal, 59:166-7.

Satyavani M, Chinnaya Rao KN. 1993. Live male adult Loa loa in the anterior chamber of the eye: a case report. Indian J Pathol Microbiol, 36:154-7.

Vedy J, Queguiner P, Graveline J, et al. 1988. [Précis d'ophtalmologie tropicale.] Beautiran: Diffusion Generale De Librairie. 
